\title{
Research on the Preference of Consumers for Black Fungus Based on Conjoint Analysis Approach
}

\author{
WANG Chunying ZHANG Chunliang \\ School of Economics and Management for Jilin Agricultural Science and Technology University \\ Jilin 132101
}

\begin{abstract}
Taking the consumers in Jilin City as the investigation objects, and then by means of in-depth interview, this paper confirms the main factors local consumers took into account when purchasing black fungus, and then uses conjoint analysis approach to confirm the main factors consumers took into account when purchasing black fungus, and its importance. Finally, combining with the conclusion of consumers' preference for purchasing black fungus, the paper puts forward relevant suggestions for black fungus planting bases, retailers and industrial associations to establish well-known brands, enhance black fungus publicity strength, establish a product rating system, exploit an sales channel and upgrade black fungus product package, etc.
\end{abstract}

Keywords-Conjoint analysis approach; Black fungus; Purchasing preference; Influencing factors

\section{INTRODUCTION}

Black fungus has the effect of benefiting qi and keeping fitness, nourishing kidney and nourishing the stomach, activating blood, anticoagulation, antithrombosis, lowering blood lipid and strong absorption effect, and in case of eating it often, it can facilitate the elimination of garbage inside the body, and the effect of preventing disease. Along with the development of black fungus industry, the improvement of planting technology and diversified varieties, the black fungus market is mixed with false products. In the process for consumers to select black fungus products, they tend to "eat healthy and nutritious food", and will consider various factors in the purchasing process, and which factors are relatively important, and for black fungus enterprises and black fungus terminal retail store, how to effectively communicate with consumers considering the relevant knowledge and information of black fungus products is very necessary.

\section{RESEARCH DESIGN}

This paper will adopt conjoint analysis approach to study the preference for consumers to select black fungus products. In the research, firstly, it is requested to confirm the product attribute and attribute level that can exert important influences on the behaviors of consumers to purchase black fungus products, and then through orthogonal experiment, confirm representative black fungus attribute and attribute level, and stimulate product portfolio; and then conduct the measurement of consumers' black fungus product preference as per the product design questionnaire simulated thereby [1-2].

\section{A. Confirmation on the attribution and attribution level of black fungus products}

Through reviewing and sorting out the relevant references about the influencing factors of agricultural products purchasing behaviors, this paper has confirmed factors such as price, the place of production, quality, and appearance when purchasing agricultural products [3-6]. But the research object is black fungus products, which belong to the fungoid products in agricultural products, but have certain difference with various types of agricultural products, so in the process of confirming the consideration about attribute, except for comprehensively considering the aforementioned inductive attributes, 33 retailers and 53 consumers of black fungus products were deeply interviewed at the same time. In the interview process of black fungus retailers and consumers, 76 interviewees mentioned that the black fungus type and appearance (thickness and black fungus size) should be considered when purchasing black fungus, and 68 interviewees also mentioned the place of production for black fungus, 54 interviewees will also consider the price when purchasing it, and 23 interviewees also mentioned the package, especially when giving black fungus products as gifts, which have certain requirements for package; in the interviewing process of 53 consumers, 46 people mentioned that they will generally consider the channel to purchase black fungus products, of which 37 consumers recommended specialty retail physical store, and 9 people also mentioned online purchasing. Through summarizing the aforementioned references and in-depth interview, this research confirms the factors considered by consumers when purchasing black fungus products as 6 attributes, including the variety, appearance, and price, place of production, package, and purchasing channel of black fungus. After confirming the aforementioned product attribute, 15 merchants and 17 consumers stated and confirmed the level of the aforementioned 6 attributes. Finally, the attribute and attribute level of black fungus products are confirmed as shown in Table 1. 


\begin{tabular}{c|c|c}
\hline Attribute & Attribute Level & No. \\
\hline \multirow{3}{*}{ Variety } & Spring black fungus & 1 \\
& Summer black fungus & 3 \\
Appearance & Autumn black fungus & 1 \\
& Common & 2 \\
Price & Better & 3 \\
& Good & 1 \\
Place of production for black fungus & Low price & 3 \\
& Medium price & 1 \\
Black fungus package & Higher price & 2 \\
& Product of geographical indication & 1 \\
Purchasing channel & Product of non-geographical indication & 2 \\
& Low-grade package & 3 \\
& Medium-grade package & 1 \\
\end{tabular}

\section{B. Black fungus product simulation}

After the attribute of black fungus products and the corresponding attribute level have been confirmed as per the aforementioned methods, the next one is simulated black fungus product portfolio. The method for the simulated product portfolio adopts full-profile method, and as per the attribute and attribute level quantities selected thereby, 324 types of black fungus product simulation portfolios can be obtained. But in case of requesting the interviewees to cooperate with the completion of evaluation about 324 types of black fungus products, this will not only increase the time pressure of interviewees, but also make it inconvenient to make statistics about the recycled data, and influence the accuracy and scientificity. Thus, in order to ensure that experimental data are more representative, this research uses SPSS21 software to conduct orthogonal experimental design and form the profile result of simulated products as shown in Table 2. 
TABLE II. Profile Design of Black fungus Simulated Products

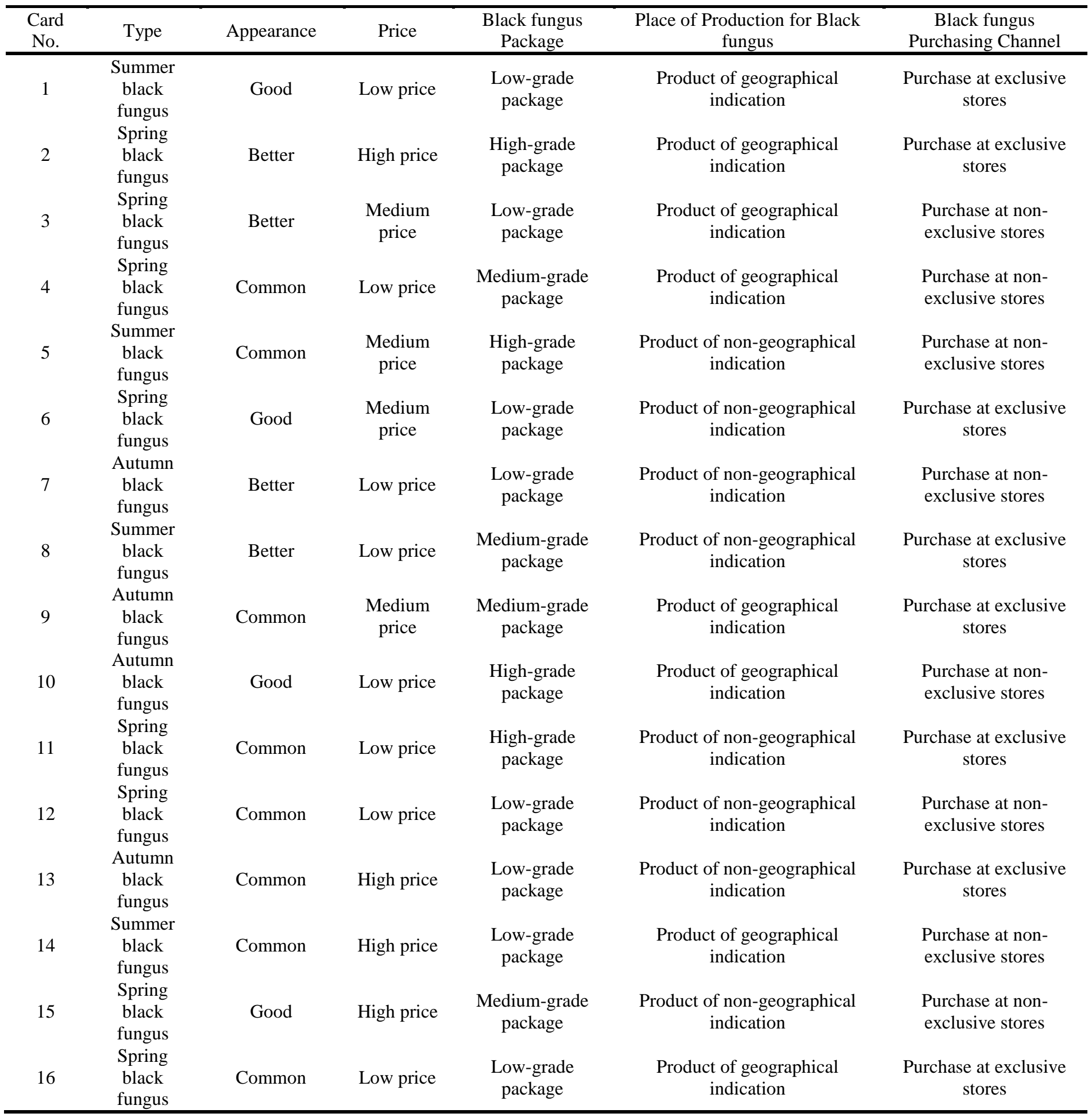




\section{DATA COLLECTION AND RESUlt ANALYSIS}

Through the orthogonal experimental design module in SPSS21 software, 16 types of black fungus simulated product portfolios are obtained. In order to better understand the main factors influencing the consumption behavior of black fungus, in the investigation, the group above 25 years old in Jilin City is mainly inquired, and then in combination with the main research objective and the basic conditions about the interviewees, the questionnaire of the research has designed two main parts, and the first part is the basic information about the interviewees, including the gender, age, education background and occupation; the second part is the main part of the questionnaire, and it mainly combines the 16 types of black fungus simulated products obtained through the earlier orthogonal experimental design, and then uses Likert Level 5 scale to measure the purchasing intention of 16 types of black fungus products, and the higher the interviewees' grade for black fungus simulated products is, the stronger the purchasing intension and the bigger the purchasing possibility will be, and after confirming the basic structure of the questionnaire, this research understands about the comprehension degree of interviewees for the questionnaire through the pretest of 25 questionnaires, and then as per the feedback of the pretest, adjusts the questionnaire expression mode, perfects the basic information options, and finally confirms the final questionnaire of the research.

\section{A. Data source and description}

From March 25 to March 27, 2018, the author sent 200 paper questionnaires at Jilin Railway Station and the surrounding communities, and totally received 198 copies, and after deleting 7 invalid questionnaires, totally 191 valid questionnaires were recovered, and the questionnaire recycling rate reached to $95.5 \%$. Among interviewees receiving the investigation, females occupied $52.9 \%$, males occupied $47.1 \%$, and the proportion for female interviewees was higher than that for male interviewees. As can be seen from the academic level of interviewees or investigators, interviewees with high school degree occupied 12.6\%; interviewees with junior college or undergraduate degree occupied $46.1 \%$, and interviewees with graduate degree and above occupied $18.3 \%$, and interviewees with other degrees occupied $23 \%$, and the coverage range was relatively wide, and can ensure the comprehensive validity of data source. As for the profession, individual jobholders occupied $16.2 \%$ of the interviewees, scientific education work occupied $16.8 \%$, national public servants occupied $16.2 \%$, interviewees of enterprises and public institutions occupied $19.9 \%$, housewife occupied $7.3 \%$, and interviewees engaged in other work occupied 23.6\%; as can be seen from the gender, age and profession, there are more professional females among the interviewees, and they can be attentive in the consumption process and pursuit for quality, and will emphasize more on the commodity details than males, and they will consider more factors more comprehensively; meanwhile, they are also the main purchasers and decision-makers for daily necessities and food.

\section{B. Consumer effectiveness evaluation}

Table 3 is the attribute importance value of the entire group output in the process of the conjoint analysis operation program and utility value of the attribute level; besides, there are also the correlation coefficients between the measurement data and the actual data. In the relevant confidents output and shown in the table, the relevant coefficients for Pearson and Kendall are respectively 0.978 and 0.953 , which are close to 1 , and indicate that the profile observation value for the simulated black fungus product has high relevance with the estimated value, and the fitting degree of the model is good. The data obtained through conjoint analysis approach is relatively reasonable, when being compared with the actual purchasing data and it can more accurately reflect the purchasing preference of interviewees in the process of purchasing black fungus products.

As can be seen from the table, the variety of black fungus is the most important factors considered by consumers, and the importance of attribute occupies $24.125 \%$; secondly, it is whether the place of production is the product of geographical indication, and the importance value is $21.368 \%$; besides, it is the appearance and price of black fungus, and the importance occupies $18.356 \%$ and $17.854 \%$ respectively; the two attributes ranked behind are purchasing channel and black fungus package, and the importance value occupies $11.268 \%$ and $7.029 \%$ respectively. As per the ranking of the aforementioned attribute importance value, it can be seen that, the factors influencing the behavior of consumers for purchasing black fungus products are respectively black fungus type or variety, place of production, appearance, price, purchasing channel and package. 
the package, and black fungus with exquisite and closed package will become the brand black fungus representatives produced at famous place of production, with high reliability degree of consumers, while black fungus with low-grade package will make consumers feel like there is purchasing risk, and will worry about the place of production and the quality.

With respect to the attribute of purchasing channel, the utility value for the attribute level of black fungus sold at exclusive stores is positive value, while the utility value for the level of black fungus sold at non-exclusive stores is negative value, which can indicate that, consumers prefer to purchase black fungus at exclusive stores. The products of exclusive stores generally can realize source traceability, and make consumers feel that the quality and after-sales are ensured; meanwhile, the service and management of exclusive stores are relatively normalized.

\section{RESEARCH CONCLUSION AND SUGGESTIONS}

\section{A. Conclusion}

When purchasing black fungus, the factors influencing the purchasing behaviors of consumers respectively include the type or variety, place of production, appearance, price, purchasing channel and package of black fungus. As a product with using value and medical value, its quality will be deeply influenced by the season, place of production, water source, and planting technology, and autumn black fungus possessing higher reputation has become the best selection for many consumers, and the black fungus planted at the places of geographical indication can be more easily recognized by consumers. As for the price, as long as the quality is good, and the taste is excellent, consumers would like to purchase it at a higher price. As for the package of black fungus, they are mostly in bulk at present; firstly, this can let consumers more intuitively see the appearance of black fungus; secondly, this can be convenient for eating, so the brand package publicity of black fungus still needs to be improved. As can be seen from the consumption concepts, products sold at exclusive stores are more credible, and merchants, especially those with big storefront, high popularity, and good service attitude are more favored by consumers.

\section{B. Suggestions}

1) Ensure black fungus quality, and build famous brand

The type of black fungus is an important attribute concerned by consumers, and autumn black fungus has the highest utility value, with thick pulp, and good taste, and since the sunlight is good and the diurnal temperature variation is big during the planting period, specific to the preference of consumers, the black fungus production bases or sales enterprises can create autumn black fungus brand through combining the variety of autumn black fungus with the regional advantages. Transmit the medical value, the best eating time and various eating methods of autumn black fungus through valid publicity approaches, and promote the popularity of autumn black fungus and autumn black fungus brand.

\section{2) Play regional advantages and enhance publicity strength}

The place of production for black fungus is the second important attribute concerned by consumers, so it can be seen that the resource advantages, and regional advantages of the place of production are very important for the influence on consumers' perceptive value for the black fungus, so black fungus industrial associations, and cultivation bases such as Changbai Mountain Area, Jilin Dunhua, Jiaohe and other areas can show the black fungus cultivation sites through online WeChat public account platform, live broadcast and other modes, deepen the consumers' understanding about the place of production, planting environment and technology of black fungus, and further promote the perceptive value of characteristic black fungus products within these areas.

\section{3) Build traceability system, and formulate rating standard}

Currently, the price of black fungus sold in the market is different, and this is because of the difference in planting manufacturers and planting costs, and merchants will deliberately increase the price, which can generate the phenomenon that consumers purchase bad-quality black fungus at high price, and good-quality black fungus at suitable price, and although such phenomenon is rare, the mode of incorrectly relaying an erroneous information can also generate a bad influence on the main production area of black fungus and the development of black fungus industry, so this requests the black fungus planting base and industrial associations to establish scientific traceability system for black fungus products, formulate black fungus quality rating standard, conduct the reasonable supervision of pricing, and perfect corresponding industrial standard.

\section{4) Expand sales channel, and upgrade product package}

Currently, the sales channel of black fungus industry mainly includes two sales mode, including the offline exclusive stores and non-exclusive stores, and through research and analysis, it can be obtained that the products of exclusive stores are more favored by consumers, with better public praise. Along with the fast development of e-business industry, the expansion of sales channel under the era of internet economy means that the offline exclusive stores operation as well as the online marketing basis should also be simultaneously conducted, and then it is requested to gradually accumulate client source and sales experience, and usher in new challenges in the future. Through in-depth interview, it can be obtained that many stores have their own stores on line, but the benefits are barely satisfactory, and the reason is that the technology operation capacity is insufficient, it cannot be trusted by consumers, the online sales language is not normalized enough, and the cutthroat competition of some merchants, etc., and this has forced some merchants to give up the online marketing. Based on this situation, the government or the relevant black fungus industrial association, etc. should organize merchants to study e-business skills, promote online service level, enhance the industrial supervision strength, strictly control the online admittance quality of black fungus industry, and realize the online and offline combined new marketing mode. 
Besides, the package of traditional black fungus products not only has simple and crude materials, but also the uncertain quality, and uncertain safety of the packing process, and with respect to the situation, retailers and manufacturers should improve the black fungus package, and the selection of package materials should be green and environmentally friendly. The product package should also highlight the characteristics about the place of production of the black fungus, highlight the indication about the product of geographical indication, and make consumers recognize the brand and then select to purchase it.

\section{ACKNOWLEDGMENT}

This paper is the periodic research achievement of the "13th Five Year Plan" Scientific Technology Research Project "Empirical Research about the Influence of Agricultural Product Regional Brand Image on Consumers' Behaviors" (Project No.: JJKH20170350SK) of the Education Department of Jilin Province, the key discipline project of Jilin Agricultural Science and Technology University "Research about the Formation Mechanism, Effect and Promotion Strategy of Agricultural Product Regional Brand in Jilin Province" (Project No.: JNYH Zi [2015] No. X082), and the project is subsidized by the Characteristic agricultural industry economic research center of the Education Department of Jilin Province,

WANG Chunying, lecturer, School of Economics and Management for Jilin Agricultural Science and Technology University

ZHANG Chunling, undergraduate student, School of Economics and Management for Jilin Agricultural Science and Technology University.

\section{REFERENCES}

[1] HAN Yudong and LIU Wei. Research Overview and Prospect of Conjoint Analysis Approach [J]. Management Modernization, 2011, 06.

[2] SUN Xiang and CHEN Yiwen. Conjoint Analysis Approach in the Research of Consumption Behaviors [J]. Advances in Psychological Science, 2005, 13 (1) 97-106.

[3] SHI Chaoguang and WANG Kai. Analysis on the Product Characteristic Factors Influencing Consumers to Make Purchasing Decisions about the Fresh Agricultural Products [J]. Acta Agriculturae Zhejiangensis, 2011, 23(1): $170-175$.

[4] LIU Zengkui. Research about the Factors Influencing the Intention of Consumers to Purchase Green Agricultural Products [D]. Dongbei University of Finance and Economics, 2016.

[5] LIU Ruifeng. Empirical Analysis on the Consumers' Characteristics and Characteristic Agricultural Product Purchasing Behaviors-Based on the Investigation Data of Beijing, Zhengzhou and Shanghai Urban Residences [J]. Chinese Rural Economy, 2014, 05.

[6] NIE Wenjing, LI Taiping and HUA Shuchun. Analysis on the Preference and Influencing Factors of Consumers for the Quality Attribute of Fresh Agricultural Products: Apple Case [J] Journal of Agricultural Economics, 2016, 09. 